European

Thyroid Journal
Eur Thyroid J 2015;4:20-25

DOI: $10.1159 / 000371883$
Received: October 23, 2014

Accepted after revision: January 5, 2015

Published online: February 11, 2015

\title{
Systemic Oxidative Stress to Nucleic Acids Is Unaltered Following Radioiodine Therapy of Patients with Benign Nodular Goiter
}

\author{
Steen J. Bonnema ${ }^{a}$ Elisabeth S. Stovgaard ${ }^{c}$ Søren Fast ${ }^{a}$ Kasper Broedbaek ${ }^{c}$ \\ Jon T. Andersen ${ }^{c}$ Allan Weimann ${ }^{c}$ Peter Grupe $^{b}$ Laszlo Hegedüs ${ }^{a}$ \\ Henrik E. Poulsen ${ }^{c, d, e}$ \\ Departments of a Endocrinology and ${ }^{b}$ Nuclear Medicine, Odense University Hospital, Odense, ${ }^{\mathrm{C}}$ Laboratory of Clinical \\ Pharmacology Q7642, Rigshospitalet, ${ }^{\mathrm{d}}$ Department of Clinical Pharmacology, Bispebjerg Hospital, and ${ }^{\mathrm{e}}$ Faculty of \\ Health Sciences, University of Copenhagen, Copenhagen, Denmark
}

\section{Key Words}

Oxidative stress - 8-oxo-7,8-dihydroguanosine .

8-oxo-7,8-dihydro-2'-deoxyguanosine · Goiter .

Radioactive iodine $\cdot$ Recombinant human TSH

\begin{abstract}
Background: Little is known about the whole body oxidative stress burden following radioactive iodine $\left({ }^{131} I\right)$ therapy of thyroid diseases. Methods: We studied 17 patients with benign nodular goiter treated with ${ }^{131}$ I therapy. The targeted thyroid dose was $50 \mathrm{~Gy}$ in 11 patients pretreated with $0.1 \mathrm{mg}$ of recombinant human TSH (rhTSH). In 6 patients, the applied thyroid dose was 100 Gy without rhTSH prestimulation. Well-established biomarkers of oxidative stress to RNA (8-oxo-7,8-dihydroguanosine; 8-oxoGuo) and DNA (8-oxo-7,8-dihydro-2'-deoxyguanosine; 8-oxodG) were measured in freshly voided morning urine (normalized against the creatinine concentration) at baseline, and 7 and 21 days after rhTSH (not followed by ${ }^{131} \mathrm{I}$ ), and 7 and 21 days after ${ }^{131}$ I therapy, respectively. Results: The baseline urinary excretions of 8-oxoGuo and 8-oxodG were $2.20 \pm 0.84$ and $1.63 \pm 0.70 \mathrm{nmol} / \mathrm{mmol}$ creatinine, respectively. We found
\end{abstract}

no significant changes in the excretion of any of the metabolites, neither after rhTSH stimulation alone nor after ${ }^{131}$ I therapy. Also, no significant differences were found between the rhTSH group (low dose, median ${ }^{131}$ I: $152 \mathrm{MBq}$ ) and the non-rhTSH group (high dose, median ${ }^{131}$ I: 419 MBq; 8-oxoGuo: $p=0.66$, 8-oxodG: $p=0.71$ ). Conclusion: Systemic oxidative stress, as detected by nucleic acids metabolites in the urine, is not increased after thyroid stimulation with $0.1 \mathrm{mg}$ of rhTSH, or after ${ }^{131}$ I therapy. Our method cannot quantify the oxidative stress induced locally in the thyroid gland, but the study supports that ${ }^{131}$ I therapy of benign nodular goiter carries no or only a minute risk of developing subsequent malignancies. It remains to be explored whether our findings also apply to hyperthyroid disorders.

(C) 2015 European Thyroid Association Published by S. Karger AG, Basel

\section{Introduction}

For many years radioactive iodine $\left({ }^{131} \mathrm{I}\right)$ has been used for treatment of nontoxic goiter, hyperthyroidism and thyroid cancer. During the last decade recombinant

\begin{tabular}{ll}
\hline KARGER 125/s & $\begin{array}{l}\text { (c) } 2015 \text { European Thyroid Association } \\
\text { Published by S. Karger AG, Basel } \\
\text { 2235-0640/15/0041-0020 } \$ 39.50 / 0\end{array}$ \\
$\begin{array}{l}\text { E-Mail karger@karger.com } \\
\text { www.karger.com/etj }\end{array}$ &
\end{tabular}

Steen J. Bonnema, MD, PhD, DMSc

Department of Endocrinology

Odense University Hospital

DK-5000 Odense C (Denmark)

E-Mail steen.bonnema@ dadlnet.dk 
human TSH (rhTSH) - a very potent stimulator of the thyroid ${ }^{131}$ I uptake - has been combined with ${ }^{131}$ I therapy in order to increase the thyroid irradiation and amplify the goiter reduction [1]. ${ }^{131}$ I therapy is a destructive treatment modality, partly mediated through the formation of free oxygen radicals leading to increased intracellular oxidative stress, and eventually cell death [2-4]. Other organs than the thyroid gland are affected by ${ }^{131} \mathrm{I}$ therapy. Chromosomal alterations in peripheral lymphocytes are seen after ${ }^{131}$ I therapy, with recovery within 24 months [5-9], but the dose-response relationship is complex [10]. Despite the fact that the risk of malignant diseases induced by ${ }^{131}$ I therapy is a matter of continuous concern, the oxidative stress burden following this treatment has only been sparsely investigated. Previous studies have shown ambiguous results, probably due to differences in study design and methods [11-14]. Furthermore, the concurrent counter regulation of the antioxidative defense mechanisms is rarely taken into account.

The urinary excretion of 8-oxo-7,8-dihydro-2'-deoxyguanosine (8-oxodG) and 8-oxo-7,8-dihydroguanosine (8-oxoGuo) is frequently used to detect oxidative stress. These nucleic acid metabolites, resulting from oxidative damage to DNA and RNA, respectively, represent highly sensitive rate estimates of the total systemic oxidative stress in vivo [15], including that from ionizing radiation. Hitherto, the impact of ${ }^{131}$ I therapy on the production of 8-oxodG and 8-oxoGuo is unrevealed, and we therefore investigated the oxidative stress burden by these urinary markers in patients treated with ${ }^{131}$ I for benign nodular goiter. In addition, we evaluated whether stimulation of the thyroid gland by rhTSH, per se and in combination with ${ }^{131}$ I therapy, increases the whole body oxidative stress.

\section{Methods}

Study Population and Design

The present study was part of a double-blind randomized controlled trial, described in detail elsewhere [16]. In brief, 90 patients suffering from compressive nodular goiter were randomized to either rhTSH-stimulated ${ }^{131} \mathrm{I}$ therapy, aiming at a thyroid irradiation dose of $50 \mathrm{~Gy}$, or placebo-stimulated ${ }^{131}$ I therapy, aiming at a thyroid dose of $100 \mathrm{~Gy}$. Randomization to placebo or rhTSH prestimulation was done in a ratio of 1:2, respectively. One injection of $0.1 \mathrm{mg}$ of rhTSH or placebo was given i.m. $24-72 \mathrm{~h}$ before ${ }^{131} \mathrm{I}$ administration. The ${ }^{131}$ I activity was calculated based on thyroid volume and $24 \mathrm{~h}{ }^{131}$ I uptake, and ${ }^{131} \mathrm{I}$ half-life. The goiter reduction after 1 year - the primary end-point of that trial - was similar in the two groups, showing that rhTSH prestimulation allows a major
Table 1. Baseline characteristics of the patients

\begin{tabular}{lcl}
\hline & $\begin{array}{l}\text { Placebo }+{ }^{131} \mathrm{I} \\
(\mathrm{n}=6)\end{array}$ & $\begin{array}{l}0.1 \mathrm{mg} \text { rhTSH + } \\
{ }^{131} \mathrm{I}(\mathrm{n}=11)\end{array}$ \\
\hline Females:males & $4: 2$ & $10: 1$ \\
Median age, years & $46(27-65)$ & $50(29-83)$ \\
Baseline thyroid volume, $\mathrm{ml}$ & $53(32-240)$ & $56(38-102)$ \\
Target thyroid ${ }^{131}$ I dose, Gy & 100 & 50 \\
Administered ${ }^{131}$ I activity, MBq & $419(245-2,560)$ & $152(93-280)$
\end{tabular}

Data are given as $\mathrm{n}$, ratios or median (range).

reduction of the radiation burden with retained efficacy in terms of goiter reduction [16].

In the last period of the trial, we recruited consecutively a subgroup of 17 patients in order to examine for the effects of rhTSH stimulation alone and in combination with ${ }^{131}$ I therapy on oxidative stress. In 11 patients, the targeted thyroid dose was $50 \mathrm{~Gy}$ and these individuals were pretreated with rhTSH in order to increase the thyroid ${ }^{131}$ I uptake. In 6 patients, the applied thyroid dose was $100 \mathrm{~Gy}$, without rhTSH prestimulation. Relevant baseline clinical and laboratory variables are shown in table 1. A freshly voided morning urine sample was collected at baseline before receiving any intervention (sample 1), and at 7 (sample 2) and 21 days (sample 3 ) after injection of either $0.1 \mathrm{mg}$ of rhTSH or placebo. Urine collection was repeated at 7 (sample 4) and 21 days (sample 5) after the ${ }^{131}$ I therapy preceded by rhTSH or placebo according to the randomization. The time points of urine collection are depicted in figure 1 and 2. The study was approved by the local ethics committee of the county of Funen, Denmark, and registered at www.clinicaltrials.gov (identifier: NCT00275171).

\section{Oxidative Stress Biomarkers}

Spot urine samples were stored at $-80^{\circ} \mathrm{C}$ until analysis for the oxidative modified guanine nucleosides 8-oxodG and 8-oxoGuo using chromatography and tandem mass spectrometry [17]. 8-oxodG and 8-oxoGuo results were normalized against the urinary creatinine concentration measured by a locally validated method. Chromatographic separation was performed using Perkin Elmer Series 200 HPLC with two pumps. The HPLC columns were a Phenomenex Prodigy ODS column $(100 \times 2 \mathrm{~mm}, 3 \mu \mathrm{m})$ and a C18 ODS guard column $(4 \times 2 \mathrm{~mm})$, both from Phenomenex (Torrance, Calif., USA). The mass spectrometry detection was performed on an API 3000 triple quadrupole mass spectrometer (Sciex, Toronto, Ont., Canada) equipped with an ESI ion source (Turbospray) operated in the positive mode [17]. The urinary excretions of 8-oxodG and 8-oxoGuo show no diurnal variation [18].

\section{Statistical Analysis}

Due to deviation from the normal distribution, the variables 8-oxodG and 8-oxoGuo were log transformed before calculation. Repeated measures ANOVA were used for analysis of variance over time. Interaction terms were added to the model to assess the interaction between the time and dose of radiation (time-dose ef- 
Fig. 1. The urinary excretion of 8-oxoGuo (a biomarker of oxidative stress to RNA) in 17 patients with nodular goiter, measured at five time points: at baseline, and 7 and 21 days after placebo or stimulation with 0.1 mg of rhTSH (case No. 1-6 and 7-17, respectively), and 7 and 21 days after ${ }^{131} \mathrm{I}$ therapy, respectively. The ${ }^{131}$ I therapy was preceded by renewed placebo or rhTSH stimulation $24-72 \mathrm{~h}$ before ${ }^{131} \mathrm{I}$ administration, according to the randomization.
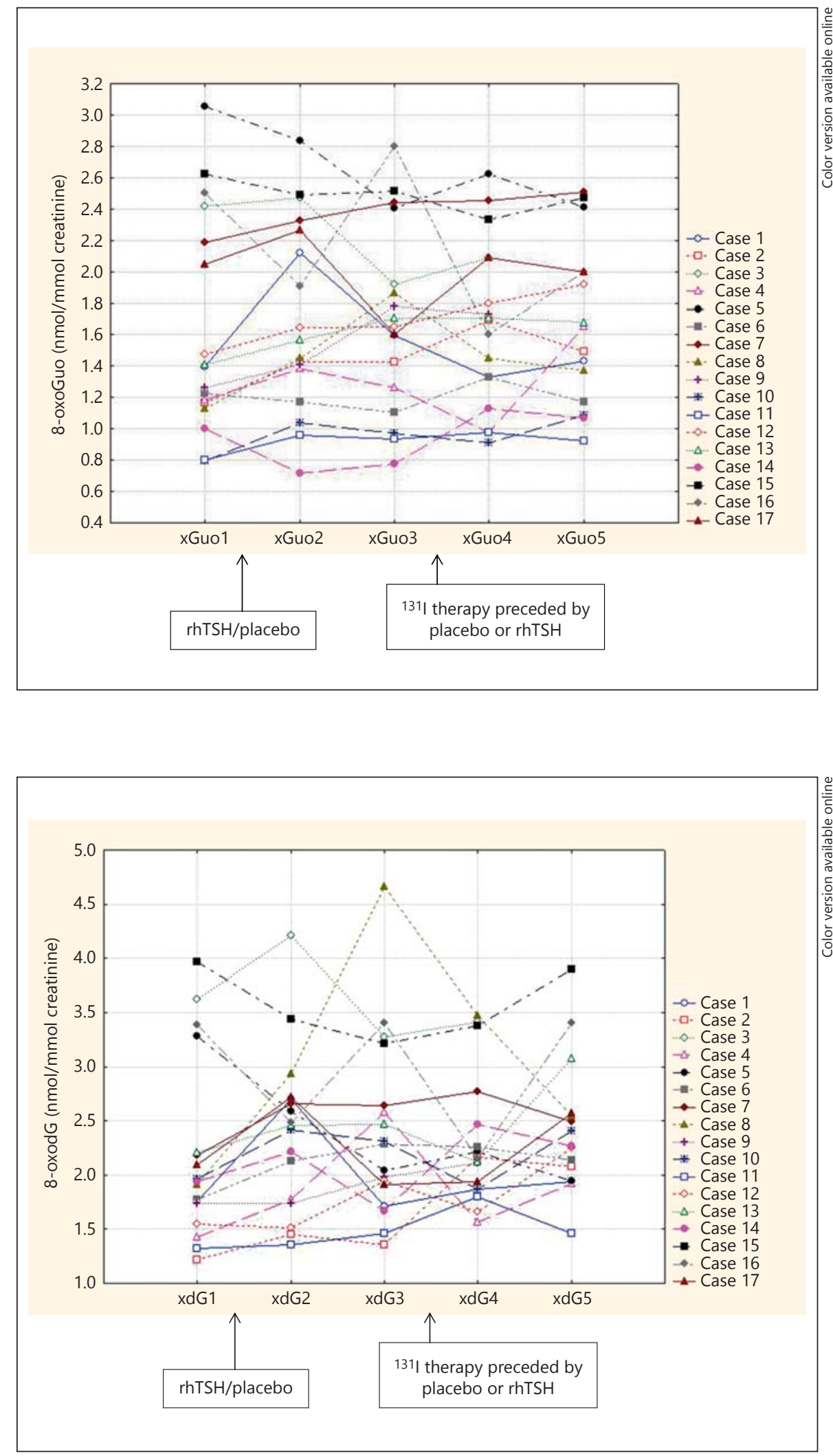

Fig. 2. The urinary excretion of 8-oxodG (a biomarker of oxidative stress to DNA) in 17 patients with nodular goiter, measured at five time points. For details, see the legend to figure 1 . 
fect). Post hoc paired t tests were used to compare differences between the samples. Statistical analyses were performed with SAS software version 9.1.3 (SAS Institute Inc., Cary, N.C., USA). Statistical significance was defined as $\mathrm{p}<0.05$. All statistical tests were two sided.

\section{Results}

The mean baseline excretion of 8-oxoGuo and 8 -oxodG was $2.20 \pm 0.84$ and $1.63 \pm 0.70 \mathrm{nmol} / \mathrm{mmol}$ creatinine, respectively. Individual values for 8-oxodG and 8 -oxoGuo are shown in figure 1 and 2 , respectively. There was no significant difference over time in either 8-oxodG or 8-oxoGuo values (repeated measures ANOVA, $\mathrm{p}=0.44$ and $\mathrm{p}=0.17$, respectively).

\section{Impact of rhTSH}

In the 11 patients stimulated with rhTSH, mean values of the oxidative stress markers measured at baseline (sample 1, 8-oxodG: $2.20 \pm 0.75 \mathrm{nmol} / \mathrm{mmol}$ creatinine, 8-oxoGuo: $1.57 \pm 0.63 \mathrm{nmol} / \mathrm{mmol}$ creatinine) $\mathrm{did}$ not change significantly when measured at day 7 (sample 2, 8-oxodG: $2.42 \pm 0.59 \mathrm{nmol} / \mathrm{mmol}$ creatinine, $\mathrm{p}=0.37$, 8-oxoGuo: $1.64 \pm 0.58 \mathrm{nmol} / \mathrm{mmol}$ creatinine, $\mathrm{p}=0.67$ ) and at day 21 after stimulation (sample 3, 8-oxodG: $2.49 \pm 0.91 \mathrm{nmol} / \mathrm{mmol}$ creatinine, $\mathrm{p}=0.31,8$-oxoGuo: $1.70 \pm 0.64 \mathrm{nmol} / \mathrm{mmol}$ creatinine, $\mathrm{p}=0.19$ ).

\section{Impact of ${ }^{131}$ I Therapy}

No differences were found when comparing mean values of all patients before and after ${ }^{131} \mathrm{I}$ therapy, i.e. sample 3 (8-oxodG: $2.45 \pm 0.94 \mathrm{nmol} / \mathrm{mmol}$ creatinine, 8-oxoGuo: $1.70 \pm 0.62 \mathrm{nmol} / \mathrm{mmol}$ creatinine) versus sample 4 (8-oxodG: $2.29 \pm 0.59 \mathrm{nmol} / \mathrm{mmol}$ creatinine, $\mathrm{p}=0.84,8$-oxoGuo: $1.65 \pm 0.52 \mathrm{nmol} / \mathrm{mmol}$ creatinine, $\mathrm{p}=0.62)$ and sample 3 versus sample 5 (8-oxodG: $2.46 \pm$ $0.64 \mathrm{nmol} / \mathrm{mmol}$ creatinine, $\mathrm{p}=0.57,8$-oxoGuo: $1.71 \pm$ $0.50 \mathrm{nmol} / \mathrm{mmol}$ creatinine, $\mathrm{p}=0.53$ ).

As a result of an increased thyroid ${ }^{131}$ I uptake and a lower target thyroid radiation dose in the rhTSH group (50 vs. $100 \mathrm{~Gy}$ in the placebo group), a significantly lower ${ }^{131} \mathrm{I}$ activity was required as compared with the group treated with ${ }^{131} \mathrm{I}$ alone (median $152 \mathrm{MBq}$ vs. median $419 \mathrm{MBq}$ ). Despite this variation in the radiation burden, no differences between the two groups were found (8-oxodG: $\mathrm{p}=0.71,8$-oxoGuo: $\mathrm{p}=0.66$ ). Furthermore, no significant dose-time interaction could be demonstrated ( 8 -oxodG: $\mathrm{p}=0.44,8$-oxoGuo: $\mathrm{p}=0.90)$.

Radioiodine Therapy and Oxidative Stress

\section{Discussion}

The present study is the first to investigate the urinary excretion of 8-oxodG and 8-oxoGuo following ${ }^{131}$ I therapy of patients with benign nontoxic nodular goiter. Although these nucleic acid metabolites are sensitive markers of DNA and RNA oxidation, we did not find any indication of an excess systemic oxidative stress load after treatment. This is reassuring since DNA and RNA oxidation are considered to be potentially mutagenic and carcinogenic.

Importantly, our method measures only the overall impact of the radiation on the body, and it cannot quantify the effect applied locally in the thyroid gland. With the huge radioactive thyroid dose there is little doubt that ${ }^{131}$ I therapy results in considerable intrathyroidal oxidative stress. Despite the fact that the thyroid irradiation by far exceeds that absorbed by most other organs during ${ }^{131}$ I therapy, the contribution from the rest of the body due to endogenous oxidative stress seems to obscure the input from a small organ such as the thyroid gland. Cellular radiation damage is mediated not solely through the formation of free oxygen radicals, but also through direct breakage of molecular bands in the DNA and RNA strands [2-4]. The negative outcome in our study may imply that the latter effect is the most significant intrathyroidal event by ${ }^{131}$ I therapy, but to what extent each of the various subcellular lesions induced by radiation contributes to the fate of the cell remains to be elucidated in future studies.

The radioactive doses applied to the thyroid gland of our patients were fairly similar to those used for treating Graves' disease. However, as the iodine kinetics vary between hyperthyroid disorders and nontoxic goiters, and since a thyroid gland affected by an autoimmune disease may have a different set-up of intracellular antioxidative defense mechanisms, our results cannot uncritically be extrapolated to patients with Graves' disease. The same reservation goes for thyroid cancer patients treated with adjuvant ${ }^{131}$ I therapy for two reasons. First, the ${ }^{131}$ I kinetics differs substantially in individuals without a thyroid gland and, second, the amount of ${ }^{131}$ I activity used for cancer patients is usually much higher (up to 3,700 MBq). However, the ${ }^{131}$ I activities in our study ranged from 93 $\mathrm{MBq}$ to as much as $2,560 \mathrm{MBq}$, and despite this huge variation no trend was seen that might indicate a positive correlation between the whole body irradiation and the load of reactive oxygen species produced. Furthermore, the patients randomized to a thyroid radiation dose of $100 \mathrm{~Gy}$ were given almost thrice as much ${ }^{131}$ I activity as the group 
randomized to $50 \mathrm{~Gy}$, without any between-group differences in the oxidative stress markers. Thus, although the number of patients in our study is small, we believe that a general oxidative modification of nucleic acids from ${ }^{131} \mathrm{I}$ therapy is unlikely to occur. It can be argued that the oxidative stress markers had normalized within a few days after ${ }^{131}$ I therapy, but recent animal studies imply that oxidative stress persists, depending on radiation quality [19]. Although similar human studies are lacking in the context of ${ }^{131}$ I therapy, measurement of 8-oxodG and 8 -oxoGuo at 7 and 21 days after treatment, as was done in our study, seems reasonable.

That ${ }^{131}$ I therapy results in no DNA or RNA damage on a whole body level is in accordance with several studies showing no or a very small risk of nonthyroid cancers following this treatment for benign thyroid diseases [ 20 23]. The few reports of opposite findings may be due to surveillance bias or the presence of confounding factors [24]. A post- ${ }^{131}$ I therapy increase in cardiovascular death - per se being associated with oxidative stress mainly in the first year after treatment [25] has also been reported, but this may be caused by the hyperthyroid state per se, rather than by the ${ }^{131}$ I therapy [26]. Indeed, hyperthyroidism may lead to a higher oxidative stress load, but the antioxidant protective enzymes are upregulated as well [27]. Nevertheless, animal as well as human studies suggest that increased free oxygen radicals may be responsible for some manifestations of hyperthyroid diseases and Graves' orbitopathy $[27,28]$. Thus, it has been shown that the urinary excretion of the DNA metabolite 8-hydroxy-2'-deoxyguanosine is increased in patients with Graves' orbitopathy, and this correlates with the disease activity and smoking status [29].

Besides the profound stimulation of the thyroid ${ }^{131} \mathrm{I}$ uptake, rhTSH results in a temporary hyperthyroid state through the secretion of thyroid hormones into the circulation [30]. This effect is dose dependent, and the modest dose of $0.1 \mathrm{mg}$ of rhTSH used in the present study may be the reason why 8-oxodG and 8-oxoGuo excretion rates were unchanged. Another explanation could be that a more prolonged hyperthyroid condition is needed to induce systemic oxidative stress detectable by this method. Recent studies have shown an association between hyperthyroidism and certain malignant diseases, and a reduced life span, respectively [31, 32]. However, it remains elusive whether oxidative damage to nucleic acids can link hyperthyroid diseases to such harmful effects on health. Focus has traditionally been on DNA oxidation but recently RNA oxidation has gained increasing attention due to its association with chronic disorders like Alzheimer's disease and diabetes mellitus [33]. Thus, the relationship between RNA oxidation and thyroid diseases might be an interesting new research field.

In conclusion, we found no induction of systemic oxidative stress in the period 1-3 weeks after rhTSH stimulation, or after ${ }^{131} \mathrm{I}$ therapy of benign nodular goiter. Although it needs to be explored whether oxidative stress markers are increased in the time period immediately following treatment, our data support current knowledge from epidemiological studies that ${ }^{131}$ I therapy of benign thyroid diseases carries no or only a minute risk of developing subsequent malignancies.

\section{Acknowledgements}

This work was supported by grants from Rigshospitalets Research Council and Region Hovedstaden, Copenhagen, Denmark. Further economic support was received from The Agnes and Knut Mørk Foundation, The Danish National Thyroid League, The Strategic Research Council and The Institute of Clinical Research at Odense University Hospital, and The Danish Agency for Science Technology and Innovation. Steen J. Bonnema is supported by the Research Council at Odense University Hospital, and Laszlo Hegedüs is supported by an unrestricted grant from the Novo Nordisk Foundation.

\section{Disclosure Statement}

All authors declare no conflicts of interest.

References 
6 Gutierrez S, Carbonell E, Galofre P, Creus A, Marcos R: Cytogenetic damage after 131-iodine treatment for hyperthyroidism and thyroid cancer: a study using the micronucleus test. Eur J Nucl Med 1999;26:1589-1596.

7 Watanabe N, Kanegane H, Kinuya S, Shuke $\mathrm{N}$, Yokoyama K, Kato H, Tomizawa G, Shimizu $M$, Funada $H$, Seto $H$ : The radiotoxicity of ${ }^{131} \mathrm{I}$ therapy of thyroid cancer: assessment by micronucleus assay of $\mathrm{B}$ lymphocytes. J Nucl Med 2004;45:608-611.

8 Dardano A, Ballardin M, Ferdeghini M, Lazzeri E, Traino C, Caraccio N, Mariani G, Barale R, Monzani F: Anticlastogenic effect of Ginkgo biloba extract in Graves' disease patients receiving radioiodine therapy. J Clin Endocrinol Metab 2007;92:4286-4289.

-9 Monteiro GO, Oliveira NG, Rodrigues AS, Laires A, Ferreira TC, Limbert E, Rueff J: Possible transient adaptive response to mitomycin C in peripheral lymphocytes from thyroid cancer patients after iodine-131 therapy. Int J Cancer 2002;102:556-561.

10 Erselcan T, Sungu S, Ozdemir S, Turgut B, Dogan D, Ozdemir O: Iodine-131 treatment and chromosomal damage: in vivo dose-effect relationship. Eur J Nucl Med Mol Imaging 2004;31:676-684.

-11 Ballardin M, Barsacchi R, Bodei L, Caraccio N, Cristofani R, Di MF, Ferdeghini M, Kusmic C, Madeddu G, Monzani F, Rossi AM, Sbrana I, Spanu A, Traino C, Barale R: Oxidative and genotoxic damage after radio-iodine therapy of Graves' hyperthyroidism. Int J Radiat Biol 2004;80:209-216.

12 Konukoglu D, Hatemi HH, Arikan S, Demir M, Akcay T: Radioiodine treatment and oxidative stress in thyroidectomised patients for differentiated thyroid cancers. Pharmacol Res 1998;38:311-315.

13 Wolfram RM, Budinsky AC, Palumbo B, Palumbo $\mathrm{R}$, Sinzinger $\mathrm{H}$ : Radioiodine therapy induces dose-dependent in vivo oxidation injury: evidence by increased isoprostane 8-Epi$\mathrm{PGF}_{2 \alpha}$. J Nucl Med 2002;43:1254-1258.

-14 Monteiro GO, Oliveira NG, Rodrigues AS, Laires A, Ferreira TC, Limbert E, Leonard A, Gerber G, Rueff J: Cytogenetic alterations and oxidative stress in thyroid cancer patients after iodine-131 therapy. Mutagenesis 2000;15: 69-75.
15 Poulsen HE, Nadal LL, Broedbaek K, Nielsen PE, Weimann A: Detection and interpretation of 8-oxodG and 8-oxoGua in urine, plasma and cerebrospinal fluid. Biochim Biophys Acta 2014; 1840:801-808.

16 Fast S, Hegedüs L, Grupe P, Nielsen VE, Bluhme C, Bastholt L, Bonnema SJ: Recombinant human thyrotropin-stimulated radioiodine therapy of nodular goiter allows major reduction of the radiation burden with retained efficacy. J Clin Endocrinol Metab 2010; 95:3719-3725.

17 Weimann A, Belling D, Poulsen HE: Quantification of 8-oxo-guanine and guanine as the nucleobase, nucleoside and deoxynucleoside forms in human urine by high-performance liquid chromatography-electrospray tandem mass spectrometry. Nucleic Acids Res 2002; 30:E7.

18 Grew IS, Cejvanovic V, Broedbaek K, Henriksen T, Petersen M, Andersen JT, JimenezSolem E, Weimann A, Poulsen HE: Diurnal variation of urinary markers of nucleic acid oxidation. Scand J Clin Lab Invest 2014;74: 336-343.

19 Datta K, Suman S, Kallakury BV, Fornace AJ Jr: Exposure to heavy ion radiation induces persistent oxidative stress in mouse intestine. PLoS One 2012;7:e42224.

20 Angusti T, Codegone A, Pellerito R, Favero A: Thyroid cancer prevalence after radioiodine treatment of hyperthyroidism. J Nucl Med 2000;41:1006-1009.

21 Franklyn JA, Maisonneuve P, Sheppard M, Betteridge J, Boyle P: Cancer incidence and mortality after radioiodine treatment for hyperthyroidism: a population-based cohort study. Lancet 1999;353:2111-2115.

22 Hall P, Berg G, Bjelkengren G, Boice JD Jr, Ericsson UB, Hallquist A, Lidberg M, Lundell G, Tennvall J, Wiklund K: Cancer mortality after iodine-131 therapy for hyperthyroidism. Int J Cancer 1992;50:886-890.

23 Ron E, Doody MM, Becker DV, Brill AB, Curtis RE, Goldman MB, Harris BS III, Hoffman DA, McConahey WM, Maxon HR, PrestonMartin S, Warshauer ME, Wong FL, Boice JD Jr: Cancer mortality following treatment for adult hyperthyroidism: Cooperative Thyrotoxicosis Therapy Follow-Up Study Group. JAMA 1998;280:347-355.
24 Metso S, Auvinen A, Huhtala H, Salmi J, Oksala $\mathrm{H}$, Jaatinen P: Increased cancer incidence after radioiodine treatment for hyperthyroidism. Cancer 2007;109:1972-1979.

25 Franklyn JA, Maisonneuve P, Sheppard MC, Betteridge J, Boyle P: Mortality after the treatment of hyperthyroidism with radioactive iodine. N Engl J Med 1998;338: 712-718.

26 Ross DS: Radioiodine therapy for hyperthyroidism. N Engl J Med 2011;364:542-550.

-27 Marcocci C, Leo M, Altea MA: Oxidative stress in Graves' disease. Eur Thyroid J 2012; 1:80-87.

28 Hara H, Sato R, Ban Y: Production of 8-OHdG and cytochrome $\mathrm{c}$ by cultured human mononuclear cells in patients with autoimmune thyroid disease. Endocr J 2001;48: 671-675.

29 Tsai CC, Cheng CY, Liu CY, Kao SC, Kau HC, Hsu WM, Wei YH: Oxidative stress in patients with Graves' ophthalmopathy: relationship between oxidative DNA damage and clinical evolution. Eye (Lond) 2009;23:17251730.

30 Fast S, Nielsen VE, Bonnema SJ, Hegedüs L: Dose-dependent acute effects of recombinant human TSH (rhTSH) on thyroid size and function: comparison of $0.1,0.3$ and $0.9 \mathrm{mg}$ of rhTSH. Clin Endocrinol (Oxf) 2010;72: 411-416.

31 Brandt F, Almind D, Christensen K, Green A, Brix TH, Hegedüs L: Excess mortality in hyperthyroidism: the influence of preexisting comorbidity and genetic confounding: a Danish nationwide register-based cohort study of twins and singletons. J Clin Endocrinol Metab 2012;97:4123-4129.

32 Brandt F, Thvilum M, Almind D, Christensen K, Green A, Hegedüs L, Brix TH: Graves' disease and toxic nodular goiter are both associated with increased mortality but differ with respect to the cause of death: a Danish population-based register study. Thyroid 2013;23: 408-413.

33 Poulsen HE, Specht E, Broedbaek K, Henriksen T, Ellervik C, Mandrup-Poulsen T, Tonnesen M, Nielsen PE, Andersen HU, Weimann A: RNA modifications by oxidation: a novel disease mechanism? Free Radic Biol Med 2012;52:1353-1361. 